\title{
EL CICLO CINEMATOGRÁFICO DE LA TELEVISIÓN CHILENA (1965-1978): LA FORMACIÓN DE UN IMAGINARIO HISTÓRICO RESIDUAL ${ }^{1}$ \\ The cinematographic cycle of Chilean television (1965-1978): The forming of a residual historical imaginary
}

Gabriel Castillo Fadic**

Pablo Corro Pemjean**

\section{Resumen}

El presente artículo busca problematizar el modo en que la recepción local del cine programado en la televisión chilena, entre 1965 y 1978, permite replicar y prolongar, en el desfase y la anacronía, un ciclo de imaginario histórico más extenso, determinado internamente por el proyecto desarrollista e ilustrado del Estado educador, y externamente por una representación residual de los regímenes heroicos modernos y, en general, de las imágenes de occidentalidad, integrada por formatos secundarios como la serie, el ensayo histórico y la historieta. Nos proponemos analizar y comprender las diversas y ricas implicancias de esta "repetición", en los planos de la estética y de la reelaboración simbólica de la representación del mundo.

Palabras clave: Cine y televisión chilena (1965-1978), Imaginario residual, Ciclo romántico, Estética.

\section{Abstract}

The following article seeks to address the issue of the way local reception of the broadcasting of films in Chilean television, between 1965 and 1978, allows us to replicate and endure, the delay and anachronism of a broader historical imaginary cycle, determined, internally, by the development and illustrated project of an educational State; externally, by a residual representation of the modern heroic regimes, and in general, by the images of westernness, composed by secondary formats, such as TV series, the historical essay and cartoons. We propose to analyse and account for the diverse and nurturing implications of this 'replication', in the fields of aesthetics and the symbolic rewriting of the world's representation.

Key words: Cinema and Chilean television (1965-1978), Residual imaginary, Romantic cycle, Aesthetics.

El film Boys Town (Norman Taurog, 1938) fue transmitido en Chile dos veces en 1976 por Canal 4 de Televisión, el sábado 23 de marzo y el viernes 13 de julio, con

\footnotetext{
${ }^{1}$ El presente artículo tiene como base el proyecto de Investigación Fondecyt Regular No 1100394 "El ciclo cinematográfico de la televisión chilena (1965-1980): estéticas e imaginarios de la reiteración y el desfase", ejecutado entre el 2010 y el 2012. Agradecemos a Fondecyt sin cuyo financiamiento este estudio no habría sido posible.
} 
el título de fantasía Con los brazos abiertos. Su saga, Men of Boys Town (Norman Taurog, 1941) fue programada seis meses después por el mismo canal, el domingo 16 de enero de 1977 y luego al cabo de un año, el sábado 25 de marzo de 1978, esta vez con la traducción algo más literal de La ciudad de los niños. La primera de estas películas había sido estrenada en el país en salas de cine en 1940, vale decir, 36 años antes de llegar a la televisión; la segunda, en 1944, 33 años antes. Boys Town, de las dos la más marcante, estaba protagonizada por Spencer Tracy en el papel de la histórica figura del sacerdote Edward Flanagan - fundador de un hogar para niños y adolescentes en riesgo social, en Nebraska, en 1917-, y por Mickey Rooney en el papel de un redimido niño delincuente, Whitey Marsh.

Sin necesidad de establecer una relación causal es plausible notar las determinaciones significativas del film sobre los modos locales de legitimación de la actualización de la vocación social de la Iglesia. Así, por ejemplo, la figura en Chile del padre Alberto Hurtado y la epopeya de la fundación del Hogar de Cristo, no solo poseen su antecedente en un contexto teológico institucional asociado a la llamada "doctrina social", sino también en un sistema social de imaginario difuso pero eficiente, predispuesto por la emergencia del héroe cinematográfico en todos los planos de la acción humana, y materializado como una posibilidad por el cine, en la variante del sacerdote. Dentro de este sistema de imaginario social, formado en el cine y replicado más tarde por la televisión, podríamos situar entonces, como correlatos internos activos, tanto al Hogar de Cristo, fundado en octubre de 1944, como a la Ciudad del Niño, su variante laica literal (Boys Town), fundada un año antes por José Antonio Ríos, en diciembre de 1943.

Como veremos, no se trata de un caso aislado, sino de uno de los múltiples ejemplos que permite sostener la existencia de lo que hemos descrito como un "ciclo cinematográfico de imaginario", que se abre con la masificación del consumo de cine en salas en la década del 30 y se cierra al cabo de una o dos generaciones con la réplica de ese mismo cine en las pantallas de televisión, especialmente entre 1968 y 1978; vale decir, desde la masificación significativa de los aparatos receptores ${ }^{2}$ hasta la aparición del color. Este último periodo, 1968-1978, corresponde en Chile, desde la perspectiva de los estudios intermediales, a una etapa paleotelevisiva. Vale decir, a

\footnotetext{
${ }^{2} \mathrm{Si}$ bien las primeras emisiones de televisión se realizan, de manera experimental, a fines de la década del 50 (1958-1959), es recién a mediados de los 60 que estas han alcanzado una masificación significativa, pasando el número de receptores de 20 mil en enero de 1963 a 47 mil a fines del 64. Si consideramos un promedio de cuatro televidentes por receptor, el número potencial de televidentes supera a los 200 mil. Un síntoma significativo de esta masificación es la aparición, en agosto de 1965, de TV Guía, la primera revista especializada de televisión, que comenta y detalla los contenidos de la programación semanal. Hemos escogido entonces este año como punto de partida de nuestro estudio de referencia, considerando además que las dos estaciones existentes a la fecha, Canal 13 y Canal 9, programan diariamente la emisión de dos a tres films. El año 1969, en que se crea Televisión Nacional de Chile - UCV Televisión comienza también un proceso de extensión de sus transmisiones desde 1968-, el número de receptores prácticamente se ha triplicado. Ya entonces, los televidentes disponen de una oferta promedio de cinco películas diarias.
} 
una etapa donde el sistema de canales lleva pocos años de emisión y comienza una fase expansiva transmitiendo en blanco y negro, bajo el alero del Estado y las universidades como administradores y responsables de las señales. Es precisamente en esta etapa que puede advertirse un progresivo aumento de la programación de films, que pasa de 26 títulos, en 1965, a cerca de 3 mil quinientos títulos, en $1977^{3}$, que son exhibidos diariamente sin ninguna jerarquía evidente de estilo, género o año de realización. Así pueden pasar entre 8 y 40 años desde que un film es estrenado en salas hasta que es exhibido nuevamente por televisión. Se trata, en un 90 por ciento, de grandes producciones cinematográficas norteamericanas, italianas, francesas, inglesas, mexicanas o incluso japonesas, que ya habían sido exhibidas en salas de cine, y en un 10 por ciento de producciones minors, serie B, especialmente concebidas para la televisión. Ello determina que, por ejemplo, un televidente nacido en la primera mitad del siglo XX accediera al revisionado de films ya asimilados décadas atrás en su exhibición en salas. Pero determina también que un espectador nacido en la segunda mitad del siglo pudiera acceder, de manera tardía, anacrónica y condensada, por televisión, a la misma memoria cinematográfica de las generaciones precedentes. Como hemos señalado, en este caso ambos sujetos comparten un "ciclo de imaginario", vale decir, un ciclo de valores y retóricas expresivas y narrativas cinematográficas, que inducen a su vez a representaciones sociales internas comunes, de la historia y del porvenir, de los grandes acontecimientos externos y de los pequeños acontecimientos internos. El estudio, parte de cuyos resultados exponemos en el presente artículo, ha tenido entonces por objeto analizar y comprender las diversas y ricas implicancias de esta "repetición" de imaginario, en los planos de la estética y de la reelaboración simbólica de la representación del mundo. Para ello tal estudio ha debido asumir una doble complejidad estratégica.

Por una parte, en el plano del objeto, puesto que supone una prolongación del corpus estrictamente cinematográfico en otros corpus correlativos paralelos, derivados, replicantes, que abordaremos más tarde, como la serie de televisión, el discurso historiográfico o la historieta. Vale decir, que la representación simbólica desborda el sistema de los medios de representación técnica de imagen en movimiento y alcanza aquella variante masiva de la cultura letrada, libresca, híbrido gráfico de cine, literatura episódica y serie fotográfica, que es la historieta, el cómic, particularmente la serie Mampato de la revista homónima. Ella coincide productivamente con el periodo de asentamiento de la televisión en la cultura local y con el ascenso en su parrilla

\footnotetext{
${ }^{3}$ En la investigación que sirve de referencia al presente artículo, se levantó un corpus de 20 mil entradas que, considerando un porcentaje de repetición cercano al 18 por ciento, permitió establecer un acopio de más de 16 mil fichas técnicas. Ellas, reducidas a su vez por categorías de género, estilo y cualidades formales, ha determinado un universo representativo cercano a los 6 mil títulos. Recordaremos también que la emisión de películas por televisión progresa de una a dos emisiones por semana entre 1965 y 1968 a diez emisiones diarias en promedio (llegando a 15 emisiones los sábados) entre 1976 y 1978, para empezar a decaer, lentamente, el año 80, hasta donde llega nuestra investigación.
} 
programática de la exhibición de filmes, y en ella se manifiesta ética y dramáticamente la ideología del Estado educador.

Por otra parte, en el plano del método, que ha debido ajustarse a las prolongaciones y ramificaciones de su objeto a la manera de una ciencia nómada e interdisciplinaria, y que combina además, una aproximación estético-especulativa, primaria, rectora, con una aproximación cuantitativa, secundaria, con valor estadístico. La especulación teórica fundamental, estético-filosófica, ha sido la columna vertebral de nuestro método. Ella se aplica a objetos críticos bien delimitados (corpus de películas exhibidas por televisión en el periodo estudiado, series de televisión, historietas), pero a ella se ha subordinado, en un segundo momento, la confrontación con un estudio complementario, cualicuantitativo, de impacto en audiencias ${ }^{4}$. Se trata de un cruce que, como veremos, ofrece nuevas y muy ricas líneas problemáticas. Combinado a las desinencias y proyecciones del objeto central, el cine en televisión, tal cruce origina lo que hemos denominado un "método intermedial". El carácter auxiliar que atribuimos a dicho estudio de audiencias, reside en el hecho de que creemos que la encuesta remite a formas conscientes de representación y solo de modo indirecto verifica las representaciones subconscientes accesibles a la especulación.

Por último, en lo que definiremos a continuación como una cualidad "romántica", las funciones narrativas del corpus cinematográfico asimilado se volverán coherentes con un sistema de regularidades narrativas internas, propias de la representación histórica del Chile de entonces, marcada por el proyecto desarrollista e ilustrado del Estado educador, que debuta justamente en la década del 30 y que, a finales de los 70, coincidentemente con el periodo aludido, llega a su fin. Sin la exigencia de la actualidad, los consumidores de cine en televisión condensan y sintetizan tanto el tiempo interno como el tiempo externo de la narración cinematográfica, suprimen la taxonomía estética e historiográfica de la categoría (cine clásico, cine arte, cine antiguo o cine retro) y omiten la determinante de estilo de la realización, cuyos parámetros de expresión remiten en última instancia a la única diferenciación válida: la del perfil heroico. Es posible notar entonces la existencia de verdaderos ciclos de programación, que suponemos por el momento espontáneos, asociados a actores como Glenn Ford, James Stewart, Van Johnson, John Wayne, Robert Mitchum, Tyronne Power, Gary Cooper, Robert Taylor, Rock Hudson, Bette

\footnotetext{
${ }^{4}$ Para este estudio se confeccionó un cuestionario estructurado con un total de 28 preguntas — de recordación espontánea y guiada, en la modalidad de respuestas cerradas y abiertas - para ser aplicado de forma presencial al universo o público objetivo del proyecto de investigación. Se levantó un total de 304 encuestas estructuradas a una muestra aleatoria estratificada de residentes en hogares particulares del conurbio del Gran Santiago, mayores de 39 años y que recordasen haber visto cine en la televisión generalista en el ciclo de los años 1965-1980. La base de datos posee la siguiente distribución de la muestra por targets: a) Etarios $=>51 \%$ de 40 a 64 años y $49 \%$ de 65 años y más; b) Género $\Rightarrow>46,1 \%$ masculino y 53,9\% femenino y; c) Grupo socioeconómico $=>34,9 \%$ alto/medio alto (abc1-c2) y 65,1\% medio bajo/bajo (c3-d). El error máximo para el total de la muestra es de $\pm 5,7 \%$ para las proporciones, con un nivel de confianza del $95 \%$. Para el caso de los estratos (sexo, grupos de edad y GSE) este es de $\pm 8,0 \%$.
} 
Davis, Elke Sommer, Rita Hayworth, Doris Day, etc., o bien a otros perfiles heroicos relativamente identificables en la lógica del star system. La inexistencia del color favorecerá también, extraordinariamente, la homogeneidad y la homologación de la temporalidad histórica asociada al cine, y disipará en el receptor la percepción del desfase. Se trata por último de un ciclo donde la inexistencia a escala no profesional de soportes de videograbación condiciona las oportunidades de visionado, durante décadas, al azar de lo que la televisión exhibe. Las películas y sus agentes de acción adquieren de este modo un carácter aurático, en un sentido benjaminiano, erigido en el valor cultual de la experiencia estética asociada a procesos masivos de distanciamiento y nostalgia.

\section{QUÉ ES UN CICLO ROMÁNTICO}

Hemos dicho que el ciclo de imaginario estudiado puede ser calificado de Romántico, en un sentido etimológico directo, primario, relativo a la narración literaria, al romance. Lo romántico surge en Europa a mediados del siglo XVIII, como crítica y abolición de la tesis romanesca según la cual habría una cesura tajante entre la vida y la literatura, y se abre a la posibilidad concreta tanto de la verificación de lo real en el plano de la invención literaria como de la prolongación de la escritura en el mundo de la vida. El ciclo romántico no se instala, como posibilidad, en las sociedades que van a la guerra o circunnavegan el planeta conquistando continentes y trayendo historias de mundos lejanos, sino en aquellas que administran a la distancia y en la nostalgia, tales acciones, reproduciéndolas en una épica menor, en un principio de representación local, alegórico, acotado a la vida de la aldea, a la aventura de regresar a casa por un atajo, de dramatizar los gestos y los ritos de la amistad o del amor, de navegar río abajo en el corazón de la provincia, como lo hace Herder en 1769, antes de embarcarse a Francia, para constatar que ambos planos, el de la gran acción y el de la pequeña acción, convergen en el carácter insuperable de la finitud 5 .

No se trata de un principio ficcional, sino, por el contrario, de un ejercicio vital que conduce históricamente a la filosofía de la existencia y a la estética como utopía de la identidad en lo particular. El flujo del arte en la vida y de la vida en el arte se materializa en Alemania, en la segunda mitad del siglo XVIII, como el más profundo antecedente del romanticismo decimonónico ${ }^{6}$. "Las extraordinarias proezas que

\footnotetext{
${ }^{5}$ Novalis escribirá: "En cuanto doy alto sentido a lo ordinario, a lo conocido dignidad de desconocido y apariencia infinita a lo finito, con todo ello romantizo (Ich romantisiere)" (Safranski, 15).

${ }^{6}$ En un notable ensayo sobre el periodo, Rudiger Safranski sostiene que: "Las especiales condiciones sociales, políticas y geográficas de Alemania hicieron que en este país prosperaran a sus anchas los libros y las publicaciones periódicas. La ausencia de puntos urbanos de importancia como centros de la vida social favorece el aislamiento y, con ello, la complacencia en la sociabilidad imaginaria en el libro, y en la sociabilidad real a través del libro. Alemania no tenía ningún poder político que diera alas a la fantasía, ninguna capital grande llena de misterios laberínticos, ninguna colonia que estimulara el sentido de la lejanía y las aventuras en el mundo exterior" (49).
} 
habían realizado los navegantes y descubridores ingleses, los pioneros en América y los cabecillas de la Revolución francesa, el público alemán las experimentaba por lo regular en una mera reproducción y en la forma sustitutiva de la literatura" (Safranski, 49). En una carta a Merck del 11 de octubre de 1780, Goethe constata lapidariamente que "el público honorable conoce todo lo extraordinario tan sólo a través de las novelas" (citado en Safranski, 49).

El ciclo de imaginario que describimos en Chile en el presente artículo posee también la cualidad de un ciclo romántico. Este se desarrolla cuando la orientación de las acciones internas de la sociedad histórica está en parte determinada por el saber distante de acciones externas mayores, asimiladas en el consumo y administración de las proyecciones narrativas que estas generan a través de medios industriales de difusión. Los antecedentes de este proceso pueden verificarse ya en el siglo XIX en la intermediación directamente literaria: el tópico de la contención amorosa se proyecta desde Jane Austen a Blest Gana, por medio de los personajes de Martín Rivas; el del retorno vengador, desde el Alexandre Dumas de El Conde de Montecristo a Ramón Pacheco, en El puñal y la sotana o El subterráneo de los jesuitas; el de las conquistas democráticas, desde el Zola de Germinal al naturalismo realista de Baldomero Lillo. Salvo que en cada uno de estos casos, la cita se traduce en una poderosa refracción del estilo que transforma a estas variantes locales, simultáneamente, en adaptaciones y en potencias creativas (Castillo, 2003). Es cierto que, mucho antes, la identidad misma del imaginario colonial se construye sobre las perpetuas expectativas y nostalgias de las presencias vicarias de Occidente y sus grandes centros metropolitanos, pero el ciclo propiamente romántico se constituye cuando los desfases y anacronismos de la representación se disfrazan en una nueva conciencia voluntaria, pero infructuosa, de inmediatez y sincronicidad. La integración telemática es la gran cauteladora de esta expectativa difusa pero constante de integración en la sincronicidad en la medida en que los niveles objetivos de desarrollo social, económico y tecnológico en los mundos locales difieren de sus modelos de referencia. Ese desfase en la identidad y la posibilidad de la acción es también un desfase en la comprensión de la acción, cuya inscripción en el sistema cultural, percibida conscientemente como una puesta al día, es derivada en realidad como una hiperconstrucción del referente, con normas propias y cualidades de representación, de la historia, del tiempo, de la sociedad, autónomas.

Un ciclo romántico no es, en ese sentido, un contexto causal, donde un acto auténtico daría origen a un acto inauténtico (por ejemplo, la Ciudad de los Muchachos, del padre Flanagan, versus el Hogar de Cristo, del Padre Hurtado), o donde la recepción de la historicidad supuestamente externa de una obra literaria o cinematográfica determinaría el carácter pasivo de una historicidad interna. Por el contrario, el ciclo romántico supone una compleja trama de regularidades discursivas recíprocas donde los elementos residuales de los imaginarios locales se vuelven también potencias activas, creativas y expresivas. 
Nuestro estudio se centra en lo que consideramos la última etapa de este ciclo, cuando el sistema de réplica y reproducción agrega a los tres planos que comportan la narración literaria, el cine y la historieta como sistema intermedial entre la representación visual y literaria, un cuarto plano: la televisión, como un soporte secundario, pero alternativo y autónomo, a la emisión de cine.

A pesar del acopio creciente, en los últimos 20 años, de estudios retrospectivos tanto sobre la televisión chilena como sobre la producción y la recepción cinematográfica, la puesta en relación sistemática de ambos campos de trabajo constituye, hasta ahora, un ámbito de investigación inexplorado. Por ejemplo, solo entre la excelente contribución historiográfica, en 1987, de María de la Luz Hurtado [et. al.], Historia de la televisión chilena entre 1959 y 1973, y la aparición, en el 2007, del pobrísimo texto de divulgación de Fernando Acuña, Soledad Gutiérrez y Adrián Puentes (eds.), Los primeros 50 años de la televisión chilena, una producción sostenida ha abordado desde las más diversas perspectivas epistemológicas una igualmente diversa cantidad de problemas asociados a la televisión: la evolución tanto de su marco jurídico como de los paradigmas teóricos, políticos e ideológicos ${ }^{7}$ que han guiado su transición desde una televisión puramente universitaria y educativa a una televisión comercial; la evolución consecuente de sus contenidos, de su estética, de su estructura programática. Pero en todos ellos, la inclusión de una cartelera cinematográfica en la parrilla programática televisiva figura como un dato neutro y general, poco significativo, o demasiado evidente, impreciso, que se consigna difusamente en términos de porcentaje asociado, en algunos casos, a una función educativa, y en otros, a una función de entretención. A lo sumo, y particularmente en la última década, se ha abordado el problema de la difusión televisiva del cine nacional y, en un sentido más amplio, de la producción dramática y documental chilena. Algo parecido ocurre con las numerosas investigaciones realizadas, o en vías de realización, en el ámbito de los estudios de cine. Acopios historiográficos, estéticos y/o críticos de la producción chilena de ficción y de documental han dado pábulo a aproximaciones metodológicas más complejas, sobre la recepción del cine nacional y extranjero, sobre el impacto de la estética hollywoodense a mediados del siglo XX, sobre la representación de Occidente que ella suscita o determina, sobre el peso de los géneros y estilos audiovisuales en la formación de un imaginario social ${ }^{8}$. Pero,

\footnotetext{
${ }^{7}$ Véase por ejemplo: Sergio Durán, Ríe cuando todos estén tristes: televisión y sociedad chilena durante la dictadura militar, Tesis de Licenciatura en Historia (inédita), Santiago, Pontificia Universidad Católica, 2008.

${ }^{8}$ Destacamos aquí las tesis inéditas de los historiadores Nicolás Lema Habash y Joaquín Hernández (ambas para la obtención del grado de Licenciados en Estética), Recepción del cine en Chile. Una aproximación desde el discurso (1915-1930), y Cartografias y mitologías del nuevo mundo (el cine estadounidense y el imaginario de Latinoamérica), Santiago, PUC, 2007. Destacamos también la investigación Fondecyt de Fernando Purcell, Hollywood en Chile. Sociedad e imperialismo cultural norteamericano, 1908-1947, así como también la investigación de Magíster en Historia (PUC) de Camila Gatica Mizala, "Tranquilein John Wayne”. Recepción y apropiación del cine western en Chile, 1935-1945.
} 
nuevamente, tales estudios privilegian como punto de nexo con el imaginario, el estreno, el afiche en cartelera y los sistemas de distribución en salas de cine, pero no abordan ni consideran los problemas teóricos que podrían derivar de una reposición tardía o de una reiteración, en la programación televisiva. Por último, en esta contextualización, los problemas relativos a la anacronía y a la discronía en la representación de la historia, o bien a las múltiples modalidades de desfase, temporal, cultural, tecnológico, propios de los países modernistas o consumidores de modernidad, países periféricos de los grandes centros industriales y de producción tecnológica del planeta, han sido ampliamente investigados en los estudios de imaginario y representación cultural, en Chile e Iberoamérica. Pero los documentos antropológicos que han servido de objeto para ello son, preferentemente, el ensayo, el método de las ciencias humanas y la filosofía, la historiografia, y la producción artística en sus diversas expresiones.

\section{ACCIÓN MENOR E IMAGEN SECUNDARIA: DE LA SERIAL AL CINE}

Es en la producción de series para televisión donde la industria cultural, particularmente norteamericana, consigue un complejo injerto de funciones simbólicas, asociadas no a la vieja épica de lo cotidiano enunciada por los prerrománticos alemanes, sino más bien a una radical y tediosa cotidianización de todo aquello que hasta entonces, como posibilidad absoluta, se erigía en agente crítico de la acción cotidiana. Desde entonces los recursos fantásticos sobrenaturales, el poder de un genio o de una bruja, o los recursos fantásticos tecnológicos, el viaje interplanetario, la retransmisión molecular, solo tendrán por finalidad la introducción de dificultades desmedidas para la culminación serena de una jornada de trabajo, de la administración de las relaciones sociales con el vecindario, de la educación de los hijos, del itinerario de la promoción $\mathrm{y}$, por sobre todo, de los vínculos sociales laborales: un jefe es invitado a cenar, un nuevo proyecto de trabajo es presentado a los directores creativos de una empresa, se hace una demanda de aumento.

La industria televisiva cruza ambos modos, el de la posibilidad absoluta y el de la cotidianeidad como insuperable límite de la acción humana. La anticipación futurista o la retrospectiva arqueológica concurren a la administración de un presente perpetuo en Los Supersónicos (The Jetsons, 1962-1988) o en Los Picapiedras (The Flinstones, 1960-1966), actuando solo como una escenografía de estilo, como una distinción de diseño, de fantasmagoría, para un estatuto invariable de lo tecnológico. Vehículos motorizados, maquinaria pesada, aeroplanos, naves espaciales, electrodomésticos, son simplemente arqueologizados en Los Picapiedras por medio de la imposible utilización de la piedra, la madera o la fuerza animal, o bien revestidos de una proyección futurista, en Los Supersónicos, mediante materiales sintéticos, cibernéticos, volátiles, aéreos. La fantástica ubicuidad temporal y versatilidad material de lo tecnológico se presentan en ambos casos circunscritas de manera preferente al espacio doméstico, ámbito de paradójica apoteosis para una sociedad burguesa que 
identifica el bienestar con la disponibilidad plena de artefactos y que, por medio de ellos, concibe la plenitud cultural como innovación permanente de recursos mediante una gestión marginal de diseño y nuevos gadgets en sus herramientas regulares.

Aun cuando la serie televisiva procura plegarse más directamente a los géneros clásicos de aventuras, el solo hecho de su carácter episódico la obliga a la preservación de los personajes, a costa de la negociación de su componente heroico, que se remite a intervenciones de salvación y resolución estándar, y a una pérdida del gran periplo, remitido ahora a las acciones que determina la administración cotidiana de un rancho en el Oeste, como en Bonanza (1959-1973), o al enfrentamiento bélico perpetuo, sin historicidad ni tiempo, como en Combate (Combat!, 1962-1967), situada, no obstante esta última en la campaña aliada 1944-1945 posdesembarco de Normandía.

También a series clásicas de anticipación tecnológica como Flash Gordon (1954-1955) y Viaje a las estrellas (Star Trek, 1966-1969), puede oponerse la compleja presentación mixta de Perdidos en el espacio (Lost in space, 1965-1968). Allí, los escasos episodios que expresan el gran periplo corresponden a las secuencias del vuelo, del extravío espacial, y a los intentos por volver a la Tierra, que culminan siempre infructuosamente en el aterrizaje en un nuevo planeta desconocido. Una vez allí, muy pocos episodios dan cuenta de grandes desplazamientos exploratorios. Cuando no, los episodios giran en torno a los mismos argumentos que habrían servido para hablar de las vicisitudes cotidianas de una familia de clase media de cualquier suburbio norteamericano. A lo sumo el Júpiter II, la nave con forma de plato volante, se erige como un refugio interplanetario para una familia de granjeros puritanos que en el "lejano Oeste" debiera hacer frente a los ataques de un estafador, un bandolero o un grupo de guerreros apaches. En cada episodio existe la amenaza del peligro, que anuncia con una exclamación grave un robot con brazos de fuelle, manos de tenaza, tronco de tambor, pies de oruga de blindado y cabeza de ampolleta. Pero ese peligro no proviene del desconocido espacio sideral y, por el contrario, podría perfectamente haber intervenido en la vida de un rancho, o de un vecindario, camino a la escuela, o de vuelta del trabajo.

A la complejidad que estas imágenes poseen ya en el contexto sociogeográfico de sus industrias de origen, debe sumarse el anacronismo, desfase, síntesis y reelaboración simbólica que implica su programación en Chile en el periodo de expansión y consolidación de la televisión. El martes 4 de diciembre de 1965, por ejemplo, la programación publicada no solo da cuenta de la hora en que será transmitida Los Picapiedras, sino que en un gesto que desaparecerá paulatinamente recién a finales de los setenta, indica nombre y argumento del episodio. "Hoy, «Pedro de Piedradura». Decidido a alcanzar un trabajo diferente, con el fin de dejar su agobiador empleo actual, Pedro se inscribe en una escuela nocturna" (TV Guía 34). El gesto revela el proceso de adaptación que experimenta una recepción social aún habituada al seguimiento episódico en la historieta y el cine, en el consumo de este 
nuevo medio de transmisión, medio de réplica y medio de síntesis. La serie sustituye y prepara, en la importancia argumental que se le dará incluso a los más pueriles y repetitivos proyectos de animación, la réplica de los géneros cinematográficos recepcionados antes en salas entre la década del 30 y la década del 60, para reexponerlos en la saga introductoria de las series episódicas. Este modo territorial, particular, de consumo, remite en general a los ricos y complejos procesos de recepción, reelaboración y producción simbólica que, asociados a sistemas industriales y/o tecnológicos de mediación masiva, desde la imprenta hasta internet, pasando por el cine, la radio y la televisión, han determinado la formación específica de imaginarios sociales locales, nacionales o regionales. En la medida en que, históricamente, tales imaginarios han sido también el síntoma de procesos de desfase, anacronismo, adaptación y administración periférica de imágenes de Occidente, decimos que se trata de sistemas de representación paradójicos, al mismo tiempo subordinados y creativos, que hemos llamado "imaginarios residuales". En el contexto de la emisión y la recepción televisiva, el imaginario residual se dispone, fundamentalmente, como un sistema regulado por imágenes secundarias de Occidente. Secundario no quiere decir aquí de menor importancia efectiva, ni tampoco necesariamente de inferior estatus en un canon estético asociado a la jerarquía de la obra maestra. Tales imágenes son secundarias porque se sitúan, respecto de los regímenes de imágenes predominantes, explícitas, consensuadas por la teoría de los expertos o la mayoría numérica, en un área de indeterminación, de no visión, en un intersticio preconsciente de la ciencia y la opinión que, desde un segundo o tercer plano, desde su propio campo de invisibilidad, actúa paradójicamente como un poderoso agente transversalizador del imaginario histórico.

Entre el año 65 y el año 78, la programación de la serie erigida aún en un excedente épico del cine, se revierte ${ }^{9}$ para dar paso a la progresiva programación de films que se instalará, a partir de la exposición de estas imágenes secundarias de Occidente, como el nuevo y último referente de un ciclo de imaginario que abordará localmente las funciones narrativas del proyecto desarrollista chileno desde Pedro Aguirre Cerda, hasta los primeros años de dictadura militar, y la renovación radical del modelo económico durante la intervención del ministro Sergio de Castro ${ }^{10}$.

El consumo anacrónico va aparejado también, en el plano interno, de una relación indirecta, o diferida, con la contingencia histórica inmediata. Por ejemplo, no es posible establecer una relación explícita, consciente o causal, entre los debates internos relativos al estatuto presente o futuro de la televisión universitaria, las líneas editoriales de los canales y su adhesión o reacción a los proyectos políticos de turno o

\footnotetext{
${ }^{9}$ La prácticamente nula programación de cine en televisión constatada entre 1965 y 1968 es inversamente proporcional al número de seriales programadas, nacionales y extranjeras, incluyendo género de animación, las que incluso parecieran satisfacer el consumo de recursos argumentales que luego serán desarrollados en el cine.

${ }^{10}$ Ministro de Economía entre 1974 y 1976, y de Hacienda, entre 1977 y 1982. 
incluso, entre las inflexiones contingentes tan marcantes para la historia de Chile como el golpe militar de 1973, y los hábitos o regularidades objetivas de la programación cinematográfica, sus estilos, géneros predominantes y contenidos formales o narrativos ${ }^{11}$. Es como si los espacios de cine fueran imperceptibles a la acción o la coacción en el ámbito del medio televisivo local, o de las políticas de programación consideradas locales. Nuestra hipótesis es que las correlaciones deben aquí establecerse en otro ámbito de regularidades expresivas, quizás menos sincrónicas, pero igualmente significativas para la comprensión de lo que hemos caracterizado como un ciclo romántico de la historia de Chile.

Desde el año 78, con la televisión en color, la programación va a despojarse muy rápidamente del cine en blanco y negro y preservará desde entonces solo las "obras maestras" del cine clásico, en espacios erigidos explícitamente en función de su rescate y crítica. Existen altas probabilidades de que un consumidor de cine actual, espectador de salas o de televisión por cable, sea capaz de distinguir diferentes calidades de blanco y negro en las películas, diversidad no solo fundada en las capacidades técnico-fotográficas de cada época, sino en tendencias estéticas históricamente vigentes. Entre el cine de 1930 y el de fines de los 60, teóricos e investigadores de lo fotográfico en el cine, como Fabrice Revault D'Allone, reconocen paradigmas luminosos-fotográficos históricamente diversos, a saber, las luces clásica, barroca y moderna. Por ejemplo, la película El hijo de Lassie (Sylvan Simon, 1945), exhibida en blanco y negro el 4 de enero de 1978, en Canal 13, es representativa del tratamiento clásico de la luz; en cambio el filme El nido de ratas (Elia Kazan,1954), realizado en blanco y negro y exhibido de igual manera el 29 de mayo de 1971, en Canal 13, es un buen ejemplo de estilo barroco en la fotografía; por último la película Modesty Blaise (Joseph Losey, 1966), filmada en colores, pero exhibida en blanco y negro el 28 de mayo de 1971, en Canal 7, es un claro exponente del estilo luminoso cromático moderno. En cuanto a la condición homologadora o diferenciadora temporal del color, vienen al caso los mismos supuestos y excepciones, supuestos tras los cuales se considera o desestima el mayor o menor nivel de instrucción audiovisual de los públicos.

Lo que se pierde definitivamente en Chile, en la actualización de la programación de cine, es un corpus considerable de films de "segunda selección",

\footnotetext{
${ }^{11}$ Excepción a este planteamiento podría ser el espacio de Cine mexicano que programa Canal 9 entre 1971 y 1973, de filmes que habían tenido gran éxito en salas en las décadas del 50 y 60, y que según el prestigioso músico Sergio Ortega, entonces programador artístico de la estación universitaria, se suben a la parrilla con la intención de darle a ésta un sello cultural local. Otra excepción, también identificable en el canal de la Universidad de Chile, fueron los programas dedicados a cine documental, los que se pauteaban en el Departamento de Cine Experimental. Es posible encontrar en la programación de Canal 13 en los años 1969 y 1970 películas españolas y argentinas, por cierto, en una proporción infinitamente menor a la del cine estadounidense, pero su presencia es interesante, ya que casi siempre se debe a que sus protagonistas eran cantantes de moda como Raphael, Rocío Durcal, Sandro o Leonardo Favio. El fenómeno revela procesos de intermedialidad entre el cine, la televisión y radio, o la industria discográfica.
} 
muchos de ellos de gran calidad, pero difíciles de clasificar estéticamente o de asignar a la mera entretención de un público masivo. Se pierde también un ciclo de obras secundarias que aunque no satisfacen como obras individuales las expectativas de un especialista, inciden en el imaginario social y determinan masivamente los ámbitos subconscientes de la recepción. Se favorece la compresión interna y externa de la historia, se exacerban las expectativas de repetición y la nostalgia del film.

La reelaboración social de este ciclo de adaptación y réplica de imágenes secundarias de Occidente constituye la erección de un más allá fenomenal, como conjunto de nostalgias ante todos los lugares ausentes a los que se supone intuitivamente pertenecer. Estos factores contribuyen a una refracción permanente de las imágenes occidentales, a una alteración de la memoria y del registro del presente con sus mecanismos de sustitución ilustrada $\mathrm{y}$, en el siglo $\mathrm{XX}$, con su utopía modernista. Utopía que sustituye la modernidad por un proceso permanente de modernización: de adhesión a la imagen de una modernidad intraindustrial sin participar en ella y de consumo de tecnología sin producirla verdaderamente.

\section{HACIA UNA ESCRITURA INTERMEDIAL}

Es fundamental para nosotros insistir en la preeminencia del carácter filosófico especulativo del método, siguiendo la premisa adorniana, y su distanciamiento de su propio trabajo cuantitativo pionero en los estudios de audiencia, en los Estados Unidos de la década del 40. Por ello, aunque consideramos como un gesto experimental cruzar la especulación con la investigación muestral estadística, lo que de hecho nos ha traído muy ricos resultados, creemos que la encuesta remite a formas conscientes de representación y solo de modo indirecto verifica las representaciones subconscientes. Por ejemplo, no parece evidente verificar por este medio la hipótesis de una identificación existencial con los héroes narrativos en una forma personal de acción y autonarración histórica, lo que exigiría una autoconsciencia téorica improbable.

La confrontación de la especulación con el estudio cuantitativo, nos ha permitido abrir varías líneas secundarias de trabajo. Una de ellas ha sido el estudio de los comentarios y las descripciones argumentales en la programación televisiva publicada diariamente en la prensa, en las que notamos, por ejemplo, una radical autonomía y desconexión entre los encargados (periodistas por lo general) de tal programación y los más elementales conocimientos de la historia y la crítica del cine, así como una asimilación de las formas y los géneros específicos a una lectura monopolizada por los géneros dominantes. Así por ejemplo, el film Los siete samuráis, de Akira Kurosawa (1954), considerada hoy una obra paradigmática del "cine arte japonés", fue emitido en Chile por televisión, cuatro veces, el viernes 10 de mayo de 1974, el sábado 5 de octubre de 1974, el sábado 15 de noviembre de 1975 y el sábado 16 de diciembre de 1978, las cuatro ocasiones en horario nocturno. Salvo en su última fecha de emisión, todas ellas en el Canal 9 de la Universidad de Chile, el argumento es descrito en la programación del diario El Mercurio con un criterio 
significativamente precrítico: "Muestra las aventuras de un grupo de guerreros japoneses que pasan peripecias al estilo de los vaqueros del oeste. Retrata la crisis de los samuráis" (5/10/74); "Narra lo sucedido en Japón el «Día de San Bartolomé (sic)»" (15/11/75); "La película es un western trasladado al Japón y relata las aventuras de seis samuráis y un vagabundo. Humor, sentido de la tradición y espíritu de crítica complementados" (10/5/74).

Otra línea secundaria ha sido el estudio del lugar de la programación en el cuerpo de los periódicos consultados. Hemos señalado la lejanía y extrañeza de los discursos que dificultaron en la conciencia del destinatario, los televidentes chilenos de aquel periodo, tanto su articulación con los cuadros de configuración de mundo que promovían otros agentes ideológicos relevantes, como la escuela, la prensa, las manifestaciones artísticas locales, como la posibilidad de relación crítica con las contingencias locales.

La estrategia editorial de convergencia ideológica entre lo cinematográfico, lo televisivo y lo periodístico para conciliar las circunstancias de un país aislado culturalmente, segregado políticamente, y a la vez plenamente disponible en términos mercantiles, necesitó de una sobreabundante programación de films de género, especialmente de acción ${ }^{12}$, en las pantallas, reforzada en el diario con una pormenorizada información sobre sus méritos argumentales y de reparto; requirió del puzle, juego de ingenio y cultura general que retiene, que demora frente al diario con esa particular atención distraída, que Adorno identificaba como característica del consumo de la industria cultural; y por último, recurrió a reconocidas interpretaciones conservadoras del acontecer internacional referidas, por ejemplo, a la inconveniente independencia de las repúblicas negras de África ${ }^{13}$, a los efectos sociales nefastos del avance del feminismo en Europa ${ }^{14}$, o a la inquietante influencia soviética en Medio Oriente ${ }^{15}$.

Las perspectivas retrógradas, maniqueas y apocalípticas de esos artículos tenían su correlato festivo en los filmes de aventuras de blancos en tierras exóticas, en comedias de enredos amorosos con intercambios de roles entre los géneros, o en los films de espías rusos y británicos. El lector, el televidente, el espectador chileno podían acceder al mundo del que estaban descalificados políticamente, a través del

\footnotetext{
${ }^{12}$ En canal 4 de Valparaíso los viernes, sábados y domingos, antes de la programación de films en los espacios nocturnos a partir de las 21 horas, Super cine y Sólo estrenos, programaban largometrajes de género en una serie de tres espacios denominados Primer cine triple acción, Segundo cine triple acción y Tercer cine triple acción. Por ejemplo, el 1 de abril de 1978 exhibieron sucesivamente las películas Oro para el César, con Jeffrey Hunter; Tierras Bravas, con Peter Finch, y La salamandra de oro, con Trevor Howard.

${ }^{13}$ Amenaza de tormenta negra en África del Sur, por Peregrine Worsthome del The Sunday Telegraph de Londres, El Mercurio de Santiago, p. 30, lunes 13 de febrero de 1978.

${ }^{14}$ Europa y la liberación femenina, por Erich Von Kuchnelt, en El Mercurio de Santiago, p. 30, jueves 27 de febrero de 1978.

${ }^{15}$ Expansionismo soviético en Medio Oriente, por David K. Willis, The Christian Science Monitor News Service, en El Mercurio de Santiago, viernes 17 de febrero de 1978.
} 
cine; justificaban la clausura y el discurso de la autarquía moral del Estado de Chile, por las referencias ominosas del afuera que presentaban los artículos; y experimentaban la cultura como el juego del puzle, como contenidos inocentes, deshistorizados, evasivos respecto de las contingencias inmediatas ${ }^{16}$. Vale la pena notar por último que si bien la incidencia de la contingencia política en la conciencia de programación de películas es prácticamente nula, a diferencia de los espacios nacionales, algunos detalles, como el modo de exhibición de la cartelera, revelan formas sutiles, pero solapadas, probablemente subconscientes, de reelaboración política del imaginario.

Inversamente, de las 304 personas encuestadas en el estudio muestral, más o menos la mitad estimó que la oferta televisiva cinematográfica estuvo determinada por intenciones políticas durante el gobierno de Salvador Allende y la dictadura del general Augusto Pinochet. Hoy, después de realizar un registro pormenorizado de la programación cinematográfica diaria que ofrecieron los canales de televisión chilenos en ese periodo, estamos en condiciones de afirmar que esa hipótesis sobre el comportamiento ideológico de los canales no se basa más que en las inclinaciones políticas de los televidentes de antaño y en su correlativa idea, utópica o antiutópica, de una necesaria injerencia de los gobiernos en los contenidos que suministran los medios de comunicación masiva. Sin embargo, no refutamos del todo el parecer de aquellos consumidores de medios. Pese a las evidencias cuantitativas de que la política programática de los canales 9,13 y 4 de las universidades de Chile, Católica y Católica de Valparaíso, respectivamente, y de Televisión Nacional de Chile, Canal 7, fue de manera dominante y creciente la de identificar el contenido cinematográfico con la práctica de inserción de bloques de entretenimiento narrativo rentable en la jornada audiovisual, y que el producto más ajustado a esos criterios, por familiaridad histórica, cultural y mercantil con las poblaciones consumidoras de relatos, y por el volumen de sus existencias, fue siempre el cine hollywoodense, sostenemos que es posible advertir en la composición histórica de la parrilla local de ese periodo reflejos de baja intensidad de las políticas contingentes, como reflejos de ciertas prioridades culturales de los grupos que administran el Estado. Tales síntomas reaccionan a los vaivenes que sufre entonces aquella originaria doctrina de Estado, afecta a calificarse de transtemporal, transpartidista o transgubernamental, de una televisión como agente audiovisual público, de calidad, educativa, universitaria. La comprensión del cine como efecto mediático contemporáneo de la diversidad cultural, de la coexistencia y circulación global de narrativas e iconografías, o como mera reiteración de encadenamientos de imágenes y acciones sensorialmente estimulantes e ideológicamente comunes, es decir, como mecanismo de entretención económica,

\footnotetext{
${ }^{16}$ Varios de estos elementos señalados, fueron expuestos por el coinvestigador Pablo Corro en su texto Sobre el "Campo de estudios del cine en Chile": Perspectivas intermediales, en el Coloquio Cine y Sociedad, realizado por la Universidad de Chile en septiembre del 2011. 
evidencia en las programaciones de los canales el grado de fidelidad al proyecto de una televisión formativa.

Desde la televisión en tiempos de Alessandri hasta la de Pinochet se advierte el relevo de un tiempo de relativa coexistencia programática del cine hollywoodense sonoro con el cine mudo, del cine yanqui de posguerra, aquel de los géneros infiltrados de un escepticismo catastrófico, con el cine francés de preguerra y el neorrealismo italiano, por otro en el que es reconocible una presencia hegemónica del cine estadounidense y en el que se mezclan las superproducciones de las majors, con los pertrechos baratos de las minors, realizaciones de la "serie B" y producciones fílmicas específicas para televisión. En ese devenir temporal y de conciencia se infiltran en uno y otro paradigma, ya sea para reforzar su diversidad, o para irritar la hegemonía, los filmes latinoamericanos, argentinos, chilenos, mexicanos, producidos más en los centros y periodos del sueño fílmico industrial del continente ${ }^{17}$, que en tiempos y ámbitos de la renovación realista, documental y socialista de sus prácticas, tiempo denominado del "nuevo cine".

Vale la pena notar, por último, que la interdisciplinariedad del método coincide con la multiplicidad de un objeto que hemos circunscrito al cine y a la televisión, pero que se proyecta por medio de matrices narrativas a la literatura, a la historieta. Así hemos podido profundizar en lo que hemos considerado el desarrollo narrativo de sujetos o personajes colectivos construidos en una fina confrontación entre el consumo industrial de imágenes y la elaboración de imágenes internas. Es lo que hemos llamado un método intermedial. Por ejemplo, una de estas construcciones se produce en la inspiración cinematográfica de la mayoría de los proyectos de historieta infantil que, con una explícita voluntad de educación de masas, se genera en el periodo $^{18}$.

En el caso de revista Mampato, uno de los correlatos cronológicos más completos del tramo epocal estudiado, se presenta un personaje interior homónimo, que representa a un niño en edad escolar con cualidades de adulto. Los aprendizajes éticos y técnicos de su educación de colegial de clase media de Santiago se proyectan y se aplican heroicamente, gracias a la posesión secreta de una máquina del tiempo, en audaces episodios de aventuras en los que revisita los grandes hitos populares de la relación historiográfica de Occidente. En ellos se le exige actuar con valor y determinación, aplicar conocimientos científicos, resolver con prudencia y madurez los elementos en conflicto y conducir, como héroe principal, los destinos de sus coadyuvantes. Tales cualidades no se agotan, no obstante, en este personaje

\footnotetext{
${ }^{17}$ Argentina, México y, en menor medida, Brasil, desde fines de los 30 hasta fines de los 50.

${ }^{18}$ Esta línea de investigación, desarrollada durante el año 2012, fue expuesta en julio en Viena, por el profesor Gabriel Castillo, en el 54 Congreso Internacional de Americanistas, a través de la ponencia titulada "La función heroica del «niño adulto» en la historieta infantil chilena, en el ocaso del Estado educador".
} 
específico, sino que se proyectan en otros personajes de historieta, como los niños y adolescentes futbolistas profesionales de revista Barrabases (Guido Vallejos) o, más tarde, durante el gobierno de la Unidad Popular, como los niños que protagonizan Mañungo (Guillermo Durán, Guidú) y El Caleuche (Diego Echeverría y Lincoln Fuentes), en la revista Cabro Chico. La adultez del niño Mampato nos sitúa además ante modalidades narrativas estrictamente funcionales a las exigencias del proyecto histórico de Chile en los primeros dos tercios del siglo XX, lo que verifica la existencia de un ciclo de réplica de imaginario. Se trata, simultáneamente, de una ilustración técnica, en un sentido literal, material, iconográfico, y de una "subjetividad ilustrada", en un sentido filosófico e histórico, desde donde se construye una idea anacrónica de Occidente, pero también, lo reiteramos, un sistema de regularidades narrativas internas, propias de la representación histórica del Chile de entonces. El programa de la adultez funciona como proyección clásica positiva, tanto en un sentido hegeliano como comtiano, de un programa histórico personificado. Los coadyuvantes de Mampato son también Ogú, el hombre del pasado, la infancia de la humanidad, y Rena, la niña telépata del futuro, la realización absoluta de la adultez expresada como potencia, como posibilidad, en el presente del niño Mampato. La figura del niño adulto responde a la asimilación anacrónica y, al final infructuosa, de una primera fase occidental de industrialización, investida aún en la invención y operación de la tecnología, no solo para satisfacer las necesidades materiales de la población, sino todavía para definirlas y prolongarlas en la ampliación misma de las tecnologías disponibles. Esa etapa se reduce a partir de la Segunda Guerra Mundial, para orientarse al fortalecimiento de mecanismos de promoción que garanticen una extensión del consumo; consumo compensatorio a la interminable apertura de necesidades.

Como lo advierte Adorno en numerosos textos, a partir de un momento determinado, y en el contexto de un proceso generalizado de reificación, la promoción se convierte en un objeto autónomo, y determina el comienzo de un proceso de infantilización del mundo adulto. No es raro entonces que en los personajes adultos construidos en esa relación con el consumo, los niños, aún de manera incipiente cooptados por el mismo proyecto cultural, expresen paradójicamente un mayor sentido de la adultez, como por ejemplo los sobrinos de Donald o Mickey, en el imaginario Disney.

En su recepción residual y anacrónica, el niño adulto perdura hasta mediados de los 70 en el imaginario chileno, por una parte, como una prolongación del sistema de inquilinaje, donde los niños se integran a la adultez aún siendo fisiológicamente niños sin pasar por la juventud y, por otra, como una prolongación del incipiente proyecto de industrialización instalado por Pedro Aguirre Cerda con la creación de la Corfo, y continuado por todos los proyectos políticos consecuentes hasta los tres primeros años de la dictadura pinochetista. El proyecto Mampato se extingue a partir del año 76, vale decir, justamente con el fin de la exigencia heroico-tecnológica, y 
heroico ilustrada, determinada por el nuevo proyecto económico, posdesarrollista, subsidiario y neoliberal, que caracteriza, hasta el día de hoy una nueva pero no menos anómala expectativa de sincronización cultural.

\author{
Pontificia Universidad Católica de Chile* \\ Instituto de Estética \\ Av. Jaime Guzmán 3300 Providencia, Santiago (Chile) \\ gcastilf@uc.cl \\ Pontificia Universidad Católica de Chile** \\ Instituto de Estética \\ Av. Jaime Guzmán 3300 Providencia, Santiago (Chile) \\ pablo.corro@gmail.com
}

\title{
OBRAS CITADAS
}

Acuña, Fernando, Gutiérrez, Soledad y Puentes, Adrián (Eds.). Los primeros 50 años de la televisión chilena. Santiago: s/e, 2007.

Castillo Fadic, Gabriel. Las estéticas nocturnas: ensayo republicano y representación cultural en Chile e Iberoamérica. Santiago: Frasis/IEUC, 2003.

Diario El Mercurio, agosto 1965-diciembre 1980: Programación de televisión.

Durán, Sergio. Ríe cuando todos estén tristes: televisión y sociedad chilena durante la dictadura militar. Tesis de Licenciatura en Historia (inédita), Santiago: Pontificia Universidad Católica, 2008.

Gatica, Camila. "Tranquilein John Wayne". Recepción y apropiación del cine western en Chile, 1935-1945. Tesis de Magíster en Historia, Santiago: Pontificia Universidad Católica, 2012.

Hernández, Joaquín. Cartografias y mitologías del nuevo mundo (el cine estadounidense y el imaginario de Latinoamérica). Tesis de Licenciatura en Estética (inédita), Santiago: PUC, 2007.

Hurtado, María de la Luz [et. al.]. Historia de la televisión chilena entre 1959 y 1973. Santiago: Documentos/CENECA, 1989.

Lema Habash. Nicolás, Recepción del cine en Chile. Una aproximación desde el discurso (1915-1930). Tesis de Licenciatura en Estética (inédita), Santiago: Pontificia Universidad Católica, 2007.

Revault D'Allones, Fabrice. La luz en el cine. Madrid: Cátedra, 2009.

Revista TV Guía n 20, Santiago, 1965.

Safranski, Rüdiger. Romanticismo: una odisea del espíritu alemán. Barcelona: Tusquets, 2009. 